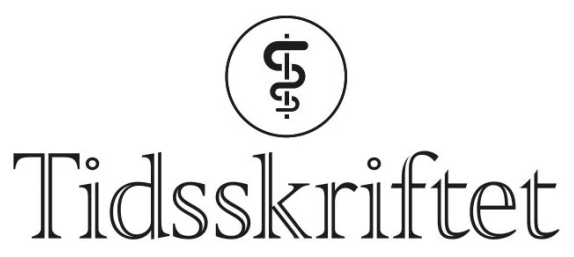

DEN NORSKE LEGEFORENING

\title{
Feilplassering av navlekatetre
}

\author{
AKTUELT
}

\section{ALF MEBERG}

Email:alfmeberg@yahoo.no

Barnesenteret

Sykehuset i Vestfold

3103 Tønsberg

\section{BAKGRUNN.}

Innleggelse av navlevene- og navlearteriekatetre er en mye brukt intervensjon hos nyfødte. Katetrene kan få en suboptimal plassering, med risiko for komplikasjoner. Hensikten med denne studien var å vurdere kateterposisjonen etter innleggelsen.

\section{MATERIALE OG METODE.}

Studien er basert på en retrospektiv gjennomgang av alle aktuelle røntgenbilder tatt av nyfødte innlagt ved neonatalenheten, Sykehuset i Vestfold i perioden f.o.m. juni 1998 t.o.m. februar 2010, med bestemmelse av kateterspissens plassering. Riktig posisjon for venekatetre ble ansett å være $\leq 10 \mathrm{~mm}$ over eller under diafragmanivå hos fullbårne, og $\leq 5$ $\mathrm{mm}$ hos premature. Arteriekatetre skulle ligge med tuppen i høyde med 6.-9. torakalvirvel (høy posisjon, foretrukket) eller 3.-4. lumbalvirvel (lav posisjon), uansett svangerskapsvarighet.

\section{RESULTATER.}

278 navlevenekatetre og 99 navlearteriekatetre ble innlagt hos totalt 298 nyfødte. Primært var $45 / 99$ ( $45 \%$ ) av navlearteriekatetrene og $77 / 278$ (28\%) av venekatetrene riktig plassert. Flere navlearteriekatetre lå for lavt $(44 \%)$ enn for høyt $(10 \%)(\mathrm{p}<0,001)$. Tilsvarende lå flere navlevenekatetre for lavt $(45 \%)$ enn for høyt $(27 \%)(\mathrm{p}<0,001)$. Ved $14(5 \%)$ av venekatetrene og seks (6\%) av arteriekatetrene var det krøll på kateteret.

\section{FORTOLKNING}

Navlekatetre blir ofte feilplassert. Dette øker fare for komplikasjoner som tromboser og sirkulasjonsforstyrrelser. Kateterposisjonen må kontrolleres med røntgenundersøkelse og om nødvendig justeres.

Innleggelse av navlevene- og navlearteriekatetre er en mye brukt intervensjon hos syke nyfødte. Navlearteriene kontraherer raskt etter fødselen (i løpet av minutter, timer) og kan være vanskelig å kateterisere, mens navlevenen passivt klapper sammen og forblir funksjonelt åpen og kateteriseringsbar i flere dager. Hos barn som er syke ved fødselen (f.eks. pga. fødselsasfyksi, prematuritet og liten vekst, medfødte misdannelser) eller blir 
syke de første levedagene (f.eks. av infeksjoner) er katetre i navlekar et godt alternativ til kanyler i perifere kar. Arteriekatetre gir mulighet for kontinuerlig invasiv blodtrykksmåling og arterielle blodprøver og kan også brukes til infusjon av væsker og medikamenter. Navlevenekatetre gir en sikker infusjonsvei for væske, elektrolytter, medikamenter og parenteral ernæring.

Navlekatetre medfører risiko for komplikasjoner. Komplikasjonene er dels forårsaket av selve innleggelsesprosedyren (falsk passasje, blødninger, perforasjoner), dels av katetrene selv (iskemi, tromboser, luftemboli, infeksjoner) og dels av infuset gjennom kateteret (perifer iskemi, tromboser) (1). For å redusere risikoen for komplikasjoner, spesielt

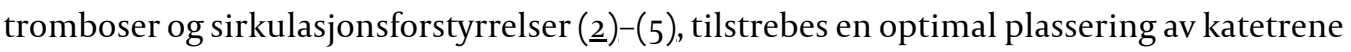
$(\underline{6}, 7$.$) .$

Hensikten med den aktuelle studien var å vurdere i hvilken grad det ved innleggelsen oppnås riktig eller feilaktig kateterposisjon, og i henhold til dette kartlegge behovet for å justere kateterposisjonen.

\section{Materiale og metoder}

Alle aktuelle røntgenbilder (røntgen thorax/abdomen) tatt av nyfødte innlagt ved neonatalenheten, Sykehuset i Vestfold - Tønsberg i perioden fra og med juni 1998 til og med februar 2010 ble gjennomgått retrospektivt. Innleggelsene var gjort av leger med erfaring med prosedyren (neonatolog, spesialister i barnesykdommer) eller av lege i utdanning under supervisjon av erfaren lege. Etter innleggelsen tas et frontalt røntgenbilde av thorax/abdomen for å bestemme kateterposisjonen og eventuelt justere denne til riktig nivå.

Kateterposisjonen (kateterspissens plassering) ble kartlagt på det første bildet tatt etter innleggelsen. Nomogram for riktig plassering av vene- $(\underline{8}, 9)$ og arteriekatetre $(\underline{8}, \underline{10})$ ble brukt med måling av skulder-umbilicus-distansen for plassering av venekateter og barnets lengde for plassering av arteriekateter. I materialet inngår ikke pasienter som fikk lagt inn navlekateter i akuttsituasjoner med hjerte-lunge-redning, når katetre legges inn blindt for volumekspansjon, stabilisering og medikamentadministrasjon, eller ved utskiftningstransfusjoner, når kateteret blir lagt der det fungerer for å trekke ut og sette inn blod, og oftest blir fjernet når transfusjonen er ferdig.

NAVLEVENEKATETRE

Riktig posisjon for venekatetre ble ansett å være $\leq 10 \mathrm{~mm}$ over eller under diafragmanivå hos fullbårne og $\leq 5 \mathrm{~mm}$ hos premature, svarende til inngangen til høyre atrium. Kateterspissen blir da liggende fritt og risikoen for tromboemboliske komplikasjoner reduseres $(\underline{1}, \underline{6})$. Katetre med spissen liggende under nedre leverkant eller i nedre tredel av leverskyggen beregnet fra kateterets krysning av nedre leverkant til diafragmanivå, ble ansett å ligge i vena umbilicalis. Katetre med spissen liggende innenfor midtre og øvre tredel av leverskyggen til > $10 \mathrm{~mm}$ under diafragma hos fullbårne og $>5 \mathrm{~mm}$ hos premature ble oppfattet som liggende i ductus venosus, og ved retning mot høyre eller venstre leverlapp som liggende henholdsvis i vena porta eller i en venstre portvenegren. Katetre som intrakardialt passerte midtlinjen med retning venstre øvre hjertekontur, ble klassifisert som liggende i venstre atrium gjennom foramen ovale eller i en av lungevenene når kateterspissen lå utenfor hjertekonturen.

\section{NAVLEARTERIEKATETRE}

For arteriekatetre ble riktig nivå ansett å være 6.-9. torakalvirvel (Th6-9) (høy posisjon) eller 3.-4. lumbalvirvel (L3-4) (lav posisjon) (1,7.). Høy kateterposisjon gir færre kliniske vaskulære komplikasjoner enn den alternative lave posisjonen (2) og er derfor den foretrukne lokalisasjonen. Tilsvarende ønsker man å unngå området Th10-L2. Her kan spissen på navlearteriekatetre gi utgangspunkt for tromboser i de store karene som utgår 
fra aorta (truncus coeliacus, nyre- og mesenterialarteriene)(1,7.). Det anvendte nomogrammet angir høy kateterposisjon svarende til Th8, og lav posisjon svarende til L4 $(\underline{8}, \underline{10})$.

Data ble anonymisert. Prosjektet er registrert som et kvalitetssikringsprosjekt ved Sykehuset i Vestfold-Tønsberg og godkjent av det lokale personvernombudet.

Statistiske beregninger ble gjort ved hjelp av khikvadrattest. En p-verdi på < o,05 ble ansett som statistisk signifikant.

\section{Resultater}

278 navlevenekatetre og 99 navlearteriekatetre ble innlagt hos totalt 298 nyfødte. 78 (26\%) fikk både arterie- og venekateter. Figur 1-3 viser røntgenbilder med ulike kateterposisjoner. I ett tilfelle fikk pasienten utilsiktet to navlevenekatetre (fig $2 a$ ) og i to tilfeller fant begge katetrene veien til samme navlearterie (fig $2 \mathrm{~b}$ og $2 \mathrm{c}$ ). Indikasjonene for innleggelse var prematuritet hos 156 (52\%), asfyksi hos 41 (14\%), infeksjon hos 37 (12\%), respirasjonsbesvær hos 24 (8\%), misdannelser hos 12 (4\%) og andre indikasjoner hos 28 (9\%).

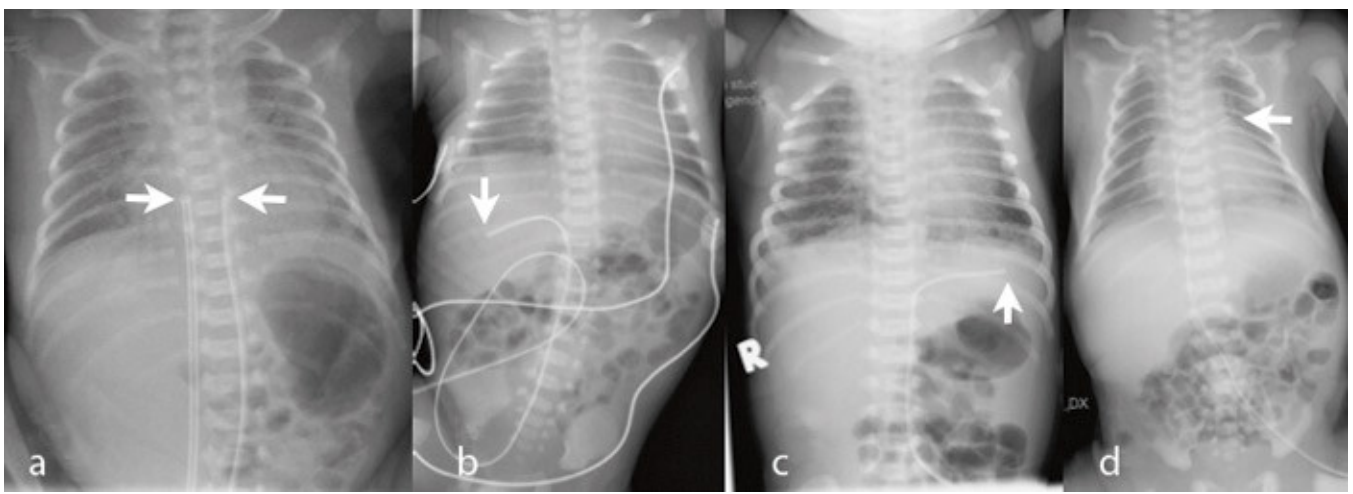

Figur 1 a) Riktig plassering av navlevenekateter (lavt i høyre atrium; venstre pil) og navlearteriekateter (Th7; høyre pil), b) navlevenekatetre i vena porta, c) navlevenekateter i en venstre portvenegren, d) navlevenekateter i en lungevene. Pilene markerer kateterspissene

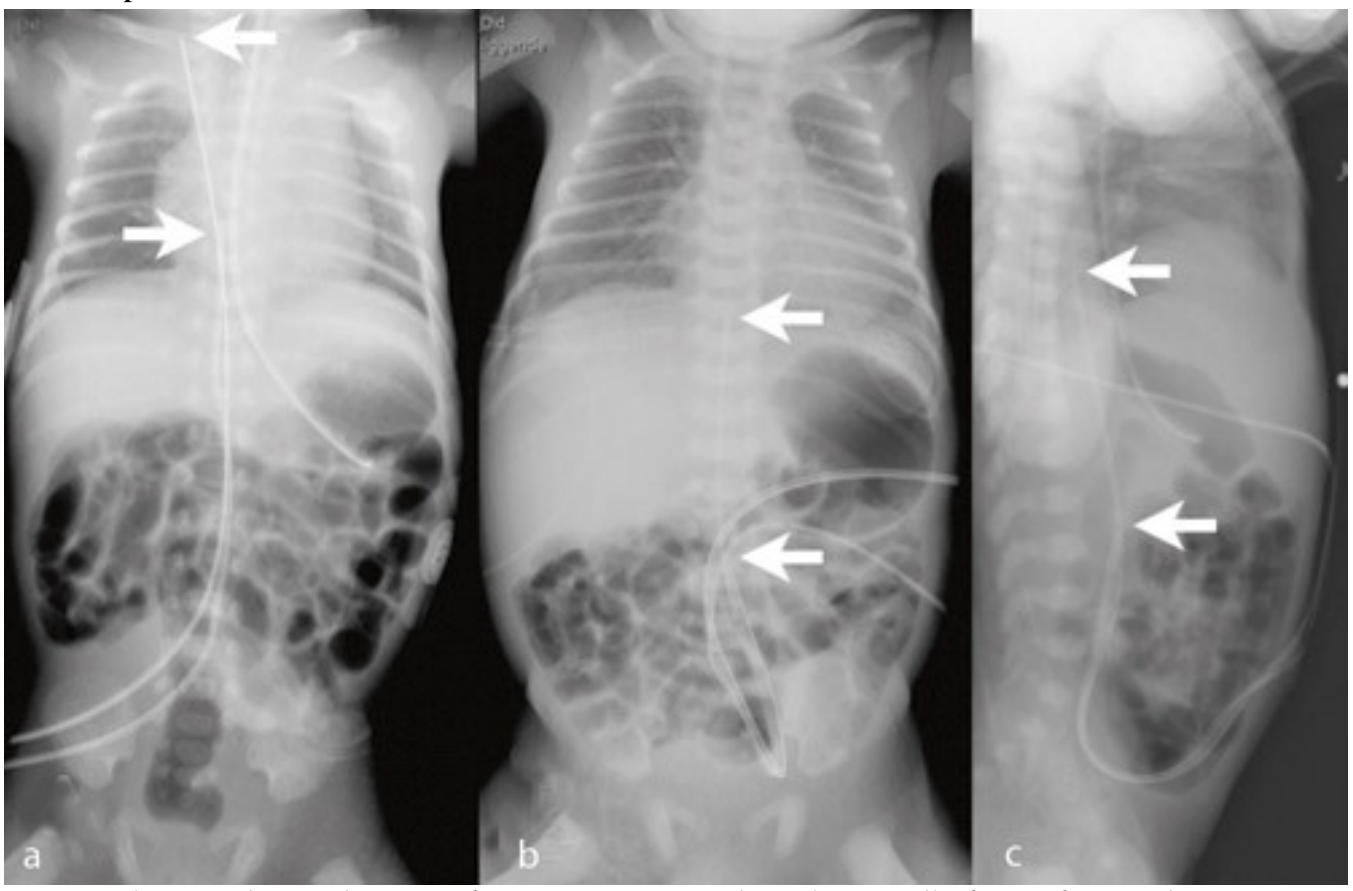

Figur 2 a) To navlevenekatetre, det ene i vena jugularis (øvre pil), det nederste i høyre atrium (nedre pil). Frontbilde (b) og sidebilde (c) av pasient med to katetre i samme navlearterie, det øverste i høyde Thy og det nederste ved L4. Pilene markerer kateterspissene. Pasientene har også innlagt ernæringssonde til ventrikkelen 


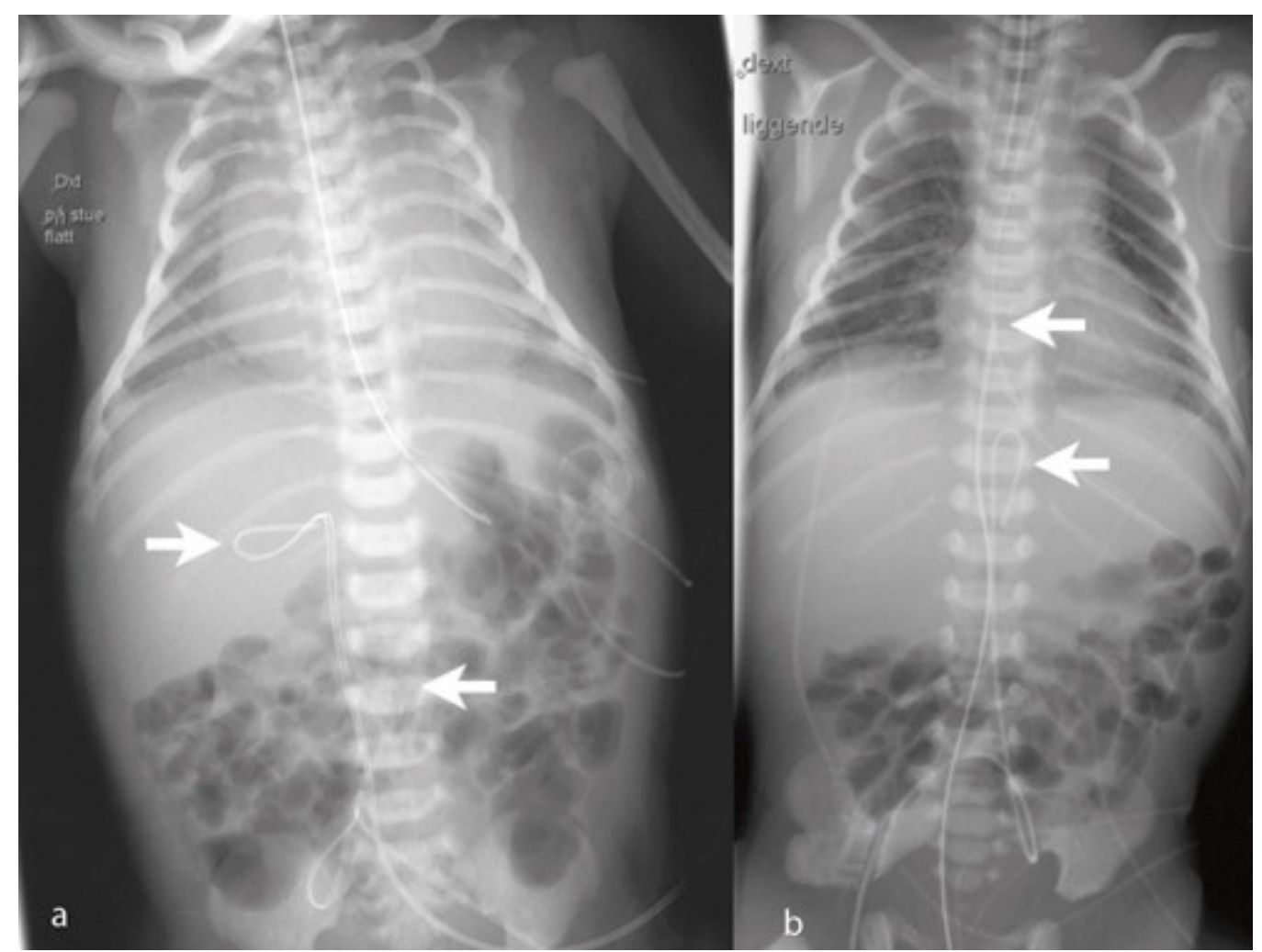

Figur 3 a) Navlevenekateter oppkrøllet i vena porta ( øverste pil; nederste pil markerer navlearteriekateter i lav posisjon, L4), b) Arteriekateter oppkrøllet i aorta (nedre pil) og navlevenekateter i høyre atrium ( øvre pil). Pasientene har også innlagt ernæringssonde til ventrikkelen

Tabell 1 angir kateterposisjonene. Av navlearteriekatetrene var 45/99 (45\%) primært riktig plassert, og 77/278 (28\%) av venekatetrene. Navlearteriekatetre lå oftere for lavt (44/99; 44\%) enn for høyt (10/99; $10 \%)$ ( $\mathrm{p}<0,001)$. Tilsvarende lå flere navlevenekatetre for lavt (126/278; $45 \%$ ) enn for høyt $(75 / 278 ; 27 \%)(\mathrm{p}<0,001)$. Hos 14 ( $5 \%$ ) av venekatetrene og seks (6\%) av arteriekatetrene var det krøll på kateteret (fig 3). For venekatetrene lå krøllen hos 11 i ductus venosus og hos tre i portveneområdet. For arteriekatetrene lå krøllen hos alle i aorta.

\section{Tabell 1}

Kateterspissens posisjon ved navlevene- og navlearteriekatetre hos 298 nyfødte

\begin{tabular}{|lllll|}
\hline & Plassering & Posisjon & Antall & $\%$ \\
\hline $\begin{array}{l}\text { Navlevenekateter } \mathrm{n}= \\
278\end{array}$ & For høyt & Vena jugularis & 1 & 0,4 \\
\hline & & Venstre atrium/lungevene & 9 & 3,2 \\
\hline & Riktig ${ }^{1}$ & Høyre atrium & 65 & 23,4 \\
\hline & For lavt & Innmunning høyre atrium & 77 & 27,7 \\
\hline & Vena porta/portvenegren & 31 & 11,2 \\
\hline & Ductus venosus & 63 & 22,7 \\
\hline $\begin{array}{l}\text { Navlearteriekateter } \mathrm{n} \\
=99\end{array}$ & Vor høyt & $\begin{array}{l}\text { Riktig (høy posisjon umbilicalis } \\
\text { foretrukket) }\end{array}$ & Aorta Th6-9 & 11,5 \\
\hline & & Aorta Th2-5 & 37 & 37,4 \\
\hline
\end{tabular}




\begin{tabular}{|lllcc|}
\hline & Plassering & Posisjon & Antall & $\%$ \\
\hline For lavt & Aorta Th10-L2 & 23 & 23,2 \\
\hline Riktig (lav posisjon) & Aorta L3-4 & 8 & 8,1 \\
\hline For lavt & L5-arteria iliaca & 16 & 16,2 \\
\hline & Arteria umbilicalis & 5 & 5,1 \\
\hline [i] & & & \\
\hline
\end{tabular}

[i] ${ }^{1} \leq 10 \mathrm{~mm}$ over eller under diafragmanivå hos fullbårne og tilsvarende $\leq_{5} \mathrm{~mm}$ hos premature

\section{Diskusjon}

Undersøkelsen viser at både navlevene- og navlearteriekatetre i stor utstrekning plasseres feil. Årsakene kan være unøyaktighet ved innleggelsen pga. feilmåling av barnets lengde og skulder-umbilicus-distanse, unøyaktig registrering av hvor langt kateteret føres inn samt anatomiske forhold hos barnet. Det var generelt en større tendens til å legge katetrene for lavt enn for høyt. Dette skyldes trolig anatomiske forhold som vanskeliggjør passasjen av arteriekatetre gjennom navle- og iliacalarteriene, og for venekatetre gjennom ductus venosus. Registrerer man ved innleggelsen at kateteret ikke lar seg føre langt nok inn, kan manipulering med litt tilbaketrekning, rotasjon og nytt avansement i noen tilfeller gjøre at det finner en mer optimal posisjon. Kateterposisjonene som er definert som korrekte i studien, er generelt akseptert som optimale for å unngå komplikasjoner $(\underline{1}, \underline{6}, 7$.$) .$

\section{KOMPLIKASJONER}

En rekke ulike komplikasjoner knyttet til navlekatetre er beskrevet (11)-(7,11)-(14). Kateterspissen og strømmen av infuset kan skade karets intima og medføre trombosering og embolier. Venekatetre som ligger intrakardialt, kan utløse arytmier (11) og gi endokarditt (12). Tromboser i portvenesystemet kan medføre portal hypertensjon (13), og levernekroser kan oppstå som følge av intrahepatisk trombose (14). Hvis spissen av navlevenekateteret ligger fritt ved inngangen til høyre atrium, anses risikoen for komplikasjoner å være lav (므). Navlearteriekatetre kan gi utgangspunkt for tromboser i de store karene som utgår fra aorta (truncus coeliacus, nyre- og mesenterialarteriene) i området Th10-L2 hvis kateteret blir liggende med spissen i dette området (1, 4, 4,7.). Høy kateterposisjon (Th6-9), som foretrukket i våre rutiner, synes å gi færre kliniske vaskulære komplikasjoner enn den alternative lave posisjonen $\left(\mathrm{L}_{3}-4\right)(\underline{2})$.

\section{KORRIGERING AV KATETERPOSISJONEN}

Røntgenkontroll gir mulighet for å kontrollere kateterposisjonen og man kan trekke tilbake katetre som er plassert for høyt. For navlevenekatetrene var dette aktuelt for $27 \%$ pga. plassering for langt inn i høyre atrium, venstre atrium, vena jugularis eller lungevene. I tillegg måtte $11 \%$ i for lav posisjon trekkes ytterligere tilbake til ductus venosus pga. primær plassering i portvenesystemet. $33 \%$ av arteriekatetrene var plassert for høyt og måtte trekkes tilbake. Så mange som 1/4 av arteriekatetrene lå primært i nivå Th1o-L2, der flere av de store arteriegrenene (truncus coeliacus, nyre- og mesenterialarteriene) utgår fra aorta. I disse tilfellene måtte kateteret trekkes tilbake til den alternative lave posisjonen L34 .

Katetre som ligger for lavt har vi ikke brukt å føre lengre inn, da steriliteten ved prosedyren vil være brutt ved fiksering av kateteret og røntgenkontrollen. Hvorvidt for lavt plasserte katetre skal beholdes i samme posisjon, må vurderes ut fra nytten av kateteret i forhold til risiko for komplikasjoner. Ved for lavt plasserte arteriekatetre må barnets 
underekstremiteter observeres nøye med tanke på avbleking og cyanose. Kateteret skal fjernes umiddelbart hvis det er mistanke om kompromittert sirkulasjon $(\underline{1}, \underline{2}, 7.7$.). Fors $ø$ k på å legge inn et nytt kateter kan da vurderes.

Både navlevene- og navlearteriekatetre kan krølles opp hvis spissen fanges av karets intima (fig 3). Økt fare for intimaskade med trombosering kan da foreligge. Krøllen bør rettes ut ved å trekke kateteret tilbake.

\section{RØNTGENDIAGNOSTIKK}

Det aktuelle arbeidet understreker nødvendigheten av å kontrollere innlagte navlekatetre røntgenologisk og justere posisjonen. Frontalbilder er adekvat for slike justeringer, men er mangelfulle m.h.t. muligheten for å bestemme eksakt kateterlokalisasjon. F.eks. vil verifisering av venekateterets lokalisasjon til venstre atrium kreve sidebilde (ㅁ). De definerte optimale avstandene fra diafragma for navlevenekatetre er praktiske, men arbitrære. Det samme gjelder definisjonen for overgangen fra v. umbilicalis til ductus venosus. Mer nøyaktig kartlegging med ultralyd eller angiografi kunne ha gitt en annen klassifisering av noen av venekateterlokalisasjonene i vårt materiale. Slike undersøkelser er imidlertid unødvendig i praktisk klinisk arbeid.

\section{GENERELT}

Innleggelse av katetre i navlevene og navlearterie er gode alternativer til kanyler i perifere vener eller arterier. Der overvåking av hemodynamiske forhold med blodtrykk og arterielle blodprøver er viktig (f.eks. ved små premature, alvorlig asfyksi, fulminante infeksjoner), har arteriekatetre en viktig funksjon. I slike tilfeller vil vi ofte samtidig legge inn navlevenekateter. Perifere vener kan da spares til senere bruk. Hos mindre syke nyfødte (f.eks. ved mindre alvorlige infeksjoner, hypoglykemi, problemer med enteral ernæring) kan likeledes et venekateter være et godt alternativ til perifer venekanyle de første levedagene, og nødvendig hvis det ikke lykkes å få inn kanyle i en perifer vene.

Ofte vil man primært forsøke å legge inn både arterie- og venekateter. I mange tilfeller lykkes det ikke å få inn navlearteriekateter fordi arteriene raskt kontraherer og stanser innføringen omkring eller i kort avstand innenfor navlen. Klarer man ikke å få inn kateteret i den ene navlearterien, kan man forsøke den andre. Mislykkes kateteriseringen av arteriene, legger vi inn navlevenekateter eller perifer venekanyle og supplerer med arteriell ikke-invasiv monitorering av blodgasser $\left(\mathrm{SpO}_{2}\right.$, transkutan $\left.\mathrm{pO}_{2} / \mathrm{pCO}_{2}\right)$ som alternativ til arterielle blodprøver. Noen foretrekker rutinemessig siste alternativ for å unngå komplikasjoner med navlekatetre. Hva man velger, vil til sist avgjøres av pasientens kliniske situasjon, legens erfaring og hva man teknisk lykkes med.

Av hensyn til infeksjonsrisikoen forsøker vi vanligvis ikke med mer enn ett kateter i samme kar. Et nytt kateter vil møte samme anatomiske hinder som det første. Lar kateteret seg lett føre inn, stanses innføringen på en kateterlengde innfor navlen (hudens nivå) som nomogrammet angir som optimal plassering. Å føre kateteret bevisst for langt inn for så å trekke det tilbake i henhold til hva røntgenbildet viser, vil medføre risiko for potensielt farlig feilplassering (deriblant lesjon av myokard med hjertearytmi samt tromboser og luftembolier i cerebrale kar).

Den hyppige feilplasseringen av navlekatetre understreker nødvendigheten av å kvalitetssikre alle sider av prosedyrene for dette inngrepet: Riktige mål av barnets lengde og skulder-umbilicus-distanse, innføring av riktig kateterlengde, god fiksering for å hindre dislosering, rask røntgenkontroll og nøyaktighet i justering av kateterposisjonen.

Jeg vil takke Radiologisk avdeling, Sykehuset $i$ Vestfold - Tønsberg for adgangen til å vurdere de aktuelle røntgenbildene fra avdelingens arkiv og for tillatelse til å gjengi noen av bildene i denne artikkelen.

\section{Oppgitte interessekonflikter:}




\section{Tabell}

\begin{tabular}{|l|}
\hline Hovedbudskap \\
\hline - Navlekatetre blir ofte primært plassert feil \\
- Flere katetre blir liggende for lavt enn for høyt \\
- Kateterposisjon må kontrolleres røntgenologisk og eventuelt justeres
\end{tabular}

\section{LITTERATUR}

1. Ahluwalia JS, Brain JL, Kelsall AW. Procedures and iatrogenic disorders. I: Rennie JM, red. Roberton's textbook of neonatology. 4. utg. Philadelphia, PA: Elsevier Churchill Livingstone, 2005: 1237-72.

2. Barrington KJ. Umbilical artery catheters in the newborn: effects of position of the catheter tip. Cochrane Database Syst Rev 1999, nr. 1: CDoo0505. doi: 10.1002/14651858.CDooo505. [PubMed]

3. Goetzman BW, Stadalnik RC, Bogren HG et al. Thrombotic complications of umbilical artery catheters: a clinical and radiographic study. Pediatrics 1975; 56:374-9. [PubMed]

4. Gupta JM, Roberton NRC, Wigglesworth JS. Umbilical artery catheterization in the newborn. Arch Dis Child 1968; 43:382-7. [PubMed] [CrossRef]

5. Scott JM. Iatrogenic lesions in babies following umbilical vein catheterization. Arch Dis Child 1965; 40: 426-9. [PubMed] [CrossRef]

6. MacDonald MG. Umbilical vein catheterization. I: Fletcher MA, MacDonald MG, red. Atlas of procedures in neonatology. Phildelphia, PA: JB Lippincott, 1993: 178-87.

7. MacDonald MG. Umbilical artery catheterization. I: Fletcher MA, MacDonald MG, red. Atlas of procedures in neonatology. Phildelphia, PA: JB Lippincott, 1993: 155-74.

8. Appendix 1-2. Umbilical vessel catheterization. I: Klaus MH, Fanaroff AA. Care of the high-risk neonate. 4. utg. Philadelphia, PA: WB Saunders, 1993: 500-3.

9. Dunn P. Localization of the umbilical catheter by post-mortem measurement. Arch Dis Child 1966; 41: 69-75. [PubMed] [CrossRef]

10. Rosenfeld W, Biagtan J, Schaeffer $\mathrm{H}$ et al. A new graph for insertion of umbilical artery catheters. J Pediatr 1980: 96; 735-7. [PubMed] [CrossRef]

11. Egan EA, Eitzman DV. Umbilical vessel catheterization. Am J Dis Child 1971; 121: 213-8. [PubMed]

12. Symchych PS, Krauss AN, Winchester P. Endocarditis following intracardiac placement of umbilical venous catheters in neonates. J Pediatr 1977; 90: 287-9. [PubMed] [CrossRef]

13. Junker P, Egeblad M, Nielsen $O$ et al. Umbilical vein catheterization and portal hypertension. Acta Paediatr Scand 1976; 65: 499-504. [PubMed] [CrossRef]

14. Wiedersberg H, Pawlowski P. Anaemic necrosis of the liver after umbilical vein catheterization. Helv Paediatr Acta 1974; 34: 53-62. [PubMed]

Publisert: 26. august 2010. Tidsskr Nor Legeforen. DOI:10.4045/tidsskr.09.1029 Manuskriptet ble mottatt 29.8. 2009 og godkjent 10.6. 2010. Medisinsk redaktør Mette Sagsveen. (C) Tidsskrift for Den norske legeforening 2023. Lastet ned fra tidsskriftet.no 26. april 2023. 